\title{
Temperature-dependent gas transport and its correlation with kinetic diameter in polymer nanocomposite membrane
}

\author{
N K ACHARYA \\ Applied Physics Department, Faculty of Technology and Engineering, The M S University of Baroda, \\ Vadodara 390 001, India \\ sarnavee@gmail.com
}

MS received 18 May 2016; accepted 5 August 2016; published online 20 May 2017

\begin{abstract}
Activation energies for permeation of polymer nanocomposite membrane have not been reported so far. A tradeoff relation between permeability and selectivity shows that as permeability increases, the selectivity decreases. Attempts have been made to see this trade-off relation at relatively higher temperature. It is found that selectivity decreases drastically with increasing temperature. A polymer-matrix composite was prepared by adding silica nanoparticles using casting method. Pure gas permeability was measured using a constant volume-variable pressure method at different temperature ranges from 35 to $70^{\circ} \mathrm{C}$. The Van't Hoff relation was used to estimate the activation energy for permeation. It is found to decrease as compared with virgin polycarbonate and it increases with kinetic diameter. For the first time, the permeability and selectivity for nanocomposite membrane are reported as a function of temperature. Activation energies for different gases have been calculated for nanocomposite membrane and compared with that of virgin polymer membrane. Decrease in activation energies for permeation $\left(E_{\mathrm{p}}\right)$ with increasing kinetic diameter has been observed for both the membranes. Selectivity reduces with temperature for both the membranes. Mechanical and thermal properties of nanocomposite membrane have been investigated using a dynamic mechanical analyser and differential scanning calorimetry, respectively. Scanning electron microscopy has been used to study surface morphology. The results show modification in physical properties due to incorporation of silica nanoparticles.
\end{abstract}

Keywords. Polymer nanocomposite membrane; transport properties; activation energy.

\section{Introduction}

Development of polymer nanocomposite has growing interest to material scientists nowadays. These new materials have various applications in multidisciplinary research, i.e., gas separation, water purification, fuel cell, nano-electronics, drug delivery, etc. Membrane-based separation process on polymer nanocomposite has been extensively discussed in literature. The extraordinary properties of nanoparticles result in a new class of composite membrane material. For industries and laboratories, membrane-based separation is widely acceptable due to low capital cost, less energy requirement and simplicity of operation. Due to distinct properties of polymers nanocomposite, much more research attention has been paid in recent years [1-5]. Incorporation of inorganic nanoparticles in polymer matrix alters the structure of the host polymer, which helps improve the separation properties [6]. Physicochemical properties of nanocomposite membrane are modified to different extents depending upon the type of filler and of course the nature of host material $[7,8]$. Transport and separation properties of carbon nanotube-mixed matrix membrane have been reviewed [9]. Apart from the advantages, membrane materials are still restricted by tradeoff relationship between permeability and selectivity [10]; however, polyimide with orhto-functional group (PIOFG) shows improved permeability without much disturbance in selectivity [11]. Activation energies of penetrant diffusion of nanocomposites were determined for various gases using polyhedral oligomeric silsesquioxane (POSS) and a polycarbonate (PC) matrix system. Bohning et al [12] have successfully demonstrated correlation between the two activation energies.

Heterogeneous or homogeneous dispersion of inorganic nanoparticles at nanometer level in a polymer matrix leads to a polymer-inorganic nanocomposite. These materials have shown their potential in overcoming the restriction on conventional permeability-selectivity trade-off relationship $[6,13]$. Transport of gas molecules through dense polymer nanocomposite membrane can be understood by different mechanisms: (i) Maxwell's model, with reduced permeability by assuming roughly spherical impermeable filler particles [14], (ii) increase in free volume, with increased permeability due to modified diffusion coefficient of penetrant [15], (iii) increase in solubility, with increased permeability due to interaction between penetrant gas and incorporated nanoparticles depending on the functionality [16] and (iv) based on nanogaps, with increased permeability due to creation of gaps between polymer chains and nanoparticles [17]. Permeation 
across membrane takes place via solution diffusion process, i.e., permeant gas absorption at upstream pressure is decided by chemical affinity of penetrant gas with polymer material of membrane, and penetrant gas diffusion inside the polymer matrix is decided by the available free volume and by the penetrant gas desorption at downstream side. For dense membranes, permeability is the product of diffusion coefficient and solubility coefficient; hence modification in either diffusion coefficient or in solubility coefficient directly alters the overall gas permeability. Metal coating on membrane substrate modifies the solubility coefficient, which results in a change in overall permeability of penetrate gas [18]. Membrane of polymer blend has different permeability behaviours depending on the ratio of blend materials [19]. Synthesis of polymer nanocomposite and penetrant determine the amount of modification in permeability. Concentration of nanofiller also plays an important role in overall permeability. Gas permeability coefficient, $P_{\mathrm{A}}$, of a pure gas (A) for polymeric membrane is given by the following formula [20]:

$$
P_{\mathrm{A}}=\frac{N l}{p_{2}-p_{1}},
$$

where $N$ is the steady-state flux across the membrane, $l$ is the membrane thickness, $p_{2}$ is the upstream pressure and $p_{1}$ is the downstream pressure. Permeability is expressed in barrers, where 1 barrer $=10^{-10}\left[\mathrm{~cm}^{3}(\mathrm{STP}) \mathrm{cm}\left(\mathrm{cm}^{2} \mathrm{~s} \mathrm{~cm}-\mathrm{Hg}\right)^{-1}\right]$. For dense polymeric membrane, while the downstream pressure is much less than the upstream pressure, permeability of penetrant is given by the solution-diffusion model as follows:

$$
P=D S,
$$

where $D$ is the diffusion coefficient and $S$ is the solubility coefficient. Diffusion coefficient can be estimated by the intercept of steady-state line and the time axis of downstream pressure $v s$. time curve [21].

$$
\theta=\frac{l^{2}}{6 D}
$$

where $\theta$ is the time lag, $l$ is the membrane thickness and $D$ is diffusion coefficient. Solubility coefficient can be determined by the ratio of permeability to diffusion coefficient. The selectivity of a polymer membrane for gas pair A and B is defined as the ratio of their permeabilities:

$$
\alpha_{\mathrm{AB}}=\frac{P_{\mathrm{A}}}{P_{\mathrm{B}}}
$$

Temperature-dependent gas permeability for estimating the activation energy for diffusion, permeation and heat of sorption for pure polymer [22] and for blends [23] has been reported. The activation energy for permeation of nanocomposite $\mathrm{PC}$ has not been studied to date. Activation energy for permeation is given by the Van't Hoff relation [22]

$$
P=P_{0} \exp \left(-E_{\mathrm{p}} / R T\right),
$$

where $P$ is the permeability coefficient, $P_{0}$ is the preexponential factor, $E_{\mathrm{p}}$ is the activation energy for permeation, $R$ is the gas constant and $T$ is the operating temperature.

In the present work, it is proposed to develop a polymermatrix composite membrane using solution cast method. The permeabilities of different gases, i.e., $\mathrm{H}_{2}, \mathrm{He}, \mathrm{CO}_{2}$ and $\mathrm{N}_{2}$, were measured using a constant volume-variable pressure method; efforts have been made to explain the gas permeation behaviour for a PC-silica nanocomposite membrane. Permeability and selectivity of pure and nanocomposite membrane will be discussed thoroughly. In this work, efforts have also been made to find the temperature-dependent gas permeation behaviour for a nanocomposite PC membrane to estimate the activation energy for permeation. Thermal and mechanical properties will be discussed using standard techniques. Surface morphology has been investigated using a scanning electron microscope (SEM).

\section{Experimental}

\subsection{Materials and preparation of polymer nanocomposite membrane}

PC membrane of about $180( \pm 2) \mu \mathrm{m}$ thick was purchased from General Electrical Co, USA. Silica nanoparticles (stock number 4860MR), $20 \mathrm{~nm}$ in average diameter, were supplied by Nanostructured \& Amorphous Materials, Inc, USA. They have density of $2.17-2.66 \mathrm{~g} \mathrm{~cm}^{-3}$ at $20^{\circ} \mathrm{C}$ and BET surface area of $160 \mathrm{~m}^{2} \mathrm{~g}^{-1}$. A $10 \mathrm{wt} \%$ and $45 \mu \mathrm{m}$ thick nanocomposite membrane was prepared by incorporation of nanoparticles in PC matrix by the solution cast method. Initially, the desired quantity of PC was dissolved in dichloromethane and stirred overnight at room temperature using a magnetic stirrer. Next day, the silica nanoparticles were dispersed by sonication in dichloromethane for 5-6 h [24]. Thereafter, the viscous PC solution and sonicated nanoparticles were mixed and kept under additional sonication for $30 \mathrm{~min}$ before casting. The mixture was poured on a flat bottomed glass surface covered with glass ring. The system was kept for evaporation overnight for complete removal of the solvent. Next day, the membrane was taken for the measurements. Uniformity in membrane thickness was confirmed by several thickness measurements using a digital thickness metre. Average thickness of $\pm 2 \mu \mathrm{m}$ was taken for permeability calculation.

\subsection{Gas permeability and selectivity}

The permeability of $\mathrm{H}_{2}, \mathrm{He}, \mathrm{CO}_{2}$ and $\mathrm{N}_{2}$ was measured using a constant volume-variable pressure method [25] at CEER, The University of Texas at Austin, USA. Permeabilities of all these gases for pure PC and PC-silica nanocomposite were measured at the temperature of $35^{\circ} \mathrm{C}$ and pressure $30 \mathrm{psia}$. The surface area and thickness of membrane were $1.96 \mathrm{~cm}^{2}$ and 
$180 \mu \mathrm{m}$, respectively, for pure PC. For PC-silica nanocomposite, the surface area and thickness of membrane were 0.26 $\mathrm{cm}^{2}$ and $43 \mu \mathrm{m}$, respectively. Upstream side of permeation cell was purged with penetrant gas and downstream side of permeation cell was evacuated with the help of a rotary pump before taking individual measurements. The following formula was used to calculate the permeability:

$$
P=\frac{V d}{p A R T}(m 1)-(m 2) .
$$

$P$ is the pure gas permeability, $V$ is total volume of downstream side, $d$ is thickness of the membrane, $p$ is upstream absolute pressure in psig, $m_{1}$ is the steady-state slope of downstream pressure $v s$. time calculated in $\mathrm{cm}-\mathrm{Hg} \mathrm{s}{ }^{-1}, m_{2}$ is the leak rate calculated in $\mathrm{cm}-\mathrm{Hg} \mathrm{s}^{-1}$ and it was maintained at $10^{-7} \mathrm{~cm}-\mathrm{Hg} \mathrm{s}^{-1}$ during the experiment. Permeability was measured in barrers, where 1 barrer $=10^{-10}\left[\mathrm{~cm}^{3}\right.$ (STP) $\left.\mathrm{cm}\left(\mathrm{cm}^{2} \mathrm{~s} \mathrm{~cm}-\mathrm{Hg}\right)^{-1}\right]$. Selectivity is the ratio of pure gas permeabilities and calculated using equation (4). Error in permeability was also calculated using the following statistical formula:

$$
\sigma_{P}=P \sqrt{\frac{\sigma_{V}^{2}}{V^{2}}+\frac{\sigma_{T}^{2}}{T^{2}}+\frac{\sigma_{p_{u p}}^{2}}{P_{u p}^{2}}+\frac{\sigma_{A}^{2}}{A^{2}}+\frac{\sigma_{l}^{2}}{l^{2}}+\frac{\sigma_{d p / d t_{s s}}^{2}-\sigma_{d p / d t_{\text {leak }}}^{2}}{\left(d p / d t_{s s}-d p / d t_{\text {leak }}\right)^{2}}} .
$$

Here, $\sigma$ is the standard deviation due to an individual experimental parameter. It is noted that the major contribution in error is due to thickness $(\sim 72 \%)$ and area $(\sim 22 \%)$. The permeabilities of all gases for neat and nanocomposite PC were measured using a constant temperature water bath between the temperature ranges of 35 and $70^{\circ} \mathrm{C}$ to estimate the activation energy for permeation.

\subsection{Differential scanning calorimetry, SEM and dynamic mechanical analyser measurements}

The glass transition temperature of the pure and nanocomposite PC was measured using a standard Q-series differential scanning calorimetry (DSC) model by TA Instruments, USA, in nitrogen atmosphere. FE-SEM image was taken using a Carl Zeiss instrument at University of Texas at Austin, USA. The membrane was coated with a thin layer of Pt-Pd alloy of about $8 \mathrm{~nm}$ thickness by sputtering prior to placing the sample in the SEM chamber. The sample beam width was kept at $4.7 \mathrm{~mm}$ and the output was monitored using an InLens detector. Dynamic mechanical analyser (DMA) measurements were performed using a TA Instruments, USA, controlled force Q800 model at $25^{\circ} \mathrm{C}$ and ramp force $1-18 \mathrm{~N}$ in nitrogen atmosphere.

\section{Results and discussion}

\subsection{Gas permeability and selectivity}

Pure gas permeability data of all gases for pure PC and $\mathrm{PC}$-silica nanocomposite membrane are shown in table 1. It was observed that the permeability of all experimental gases increases for the PC-silica nanocomposite membrane. Existence of silica nanoparticles creates excess space in the interface of polymer matrix and silica nanoparticles, which results in an increase in gas permeability. Permeation behaviour was found to be in the following order: $\mathrm{H}_{2}>\mathrm{He}>\mathrm{CO}_{2}>\mathrm{N}_{2}$ for both the pure and PC silica nanocomposite membrane. The kinetic diameter of penetrant determines the overall permeability of dense membrane. In addition, the permeabilities for the PC silica nanocomposite membrane were found to be higher than those of unfilled PC for all gases under the experimental conditions. Similar results with different wt $\%$ of silica in polysulfone have been observed by Ahn et al [26]. Error in permeability was calculated using equation (7). It was found that the error in permeability is more in the polymer nanocomposite membrane; this may be due to the smaller area exposed to the upstream pressure side and thickness of the membrane.

Statistical analysis was made after steady state at downstream side. Permeation rate after steady state is linear; hence the slope of this curve gives the information about overall permeability. Hydrogen and helium have excessively fast permeation even at low upstream pressure; hence it is difficult to find the steady state for such gases. For both hydrogen and helium, the slope decrease after incorporation of silica nanoparticles in PC matrix, while overall permeability for both the gases increases slightly. This is because the permeability coefficient is determined not only by the permeation rate but also by other parameters, i.e., exposed area and thickness also contribute. Permeation increases with increasing time from the beginning for both hydrogen and helium. Slopes of downstream pressure $v s$. time curve were calculated using standard software Origin 8 . In the present study, it reduced from $7.31 \times 10^{-5}$ to $5.61 \times 10^{-5} \mathrm{~cm}-\mathrm{Hg} \mathrm{s}^{-1}$ and for helium,

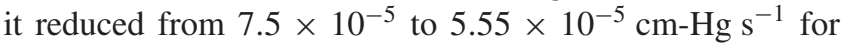

Table 1. Permeability of pure polymer and polymer nanocomposite (at $35^{\circ} \mathrm{C}, 2 \mathrm{~atm}$ ).

\begin{tabular}{lcccc}
\hline & \multicolumn{4}{c}{ Permeability (barrer) } \\
\cline { 2 - 5 } Sample & \multicolumn{1}{c}{$\mathrm{H}_{2}$} & $\mathrm{He}$ & $\mathrm{CO}_{2}$ & $\mathrm{~N}_{2}$ \\
\hline Pure PC & $13.62 \pm 0.19$ & $13.37 \pm 0.18$ & $7.70 \pm 0.10$ & $0.36 \pm 0.0056$ \\
PC-silica nanocomposite & $17.86 \pm 1.74$ & $17.51 \pm 1.71$ & $11.49 \pm 1.13$ & $1.10 \pm 0.12$ \\
\hline
\end{tabular}



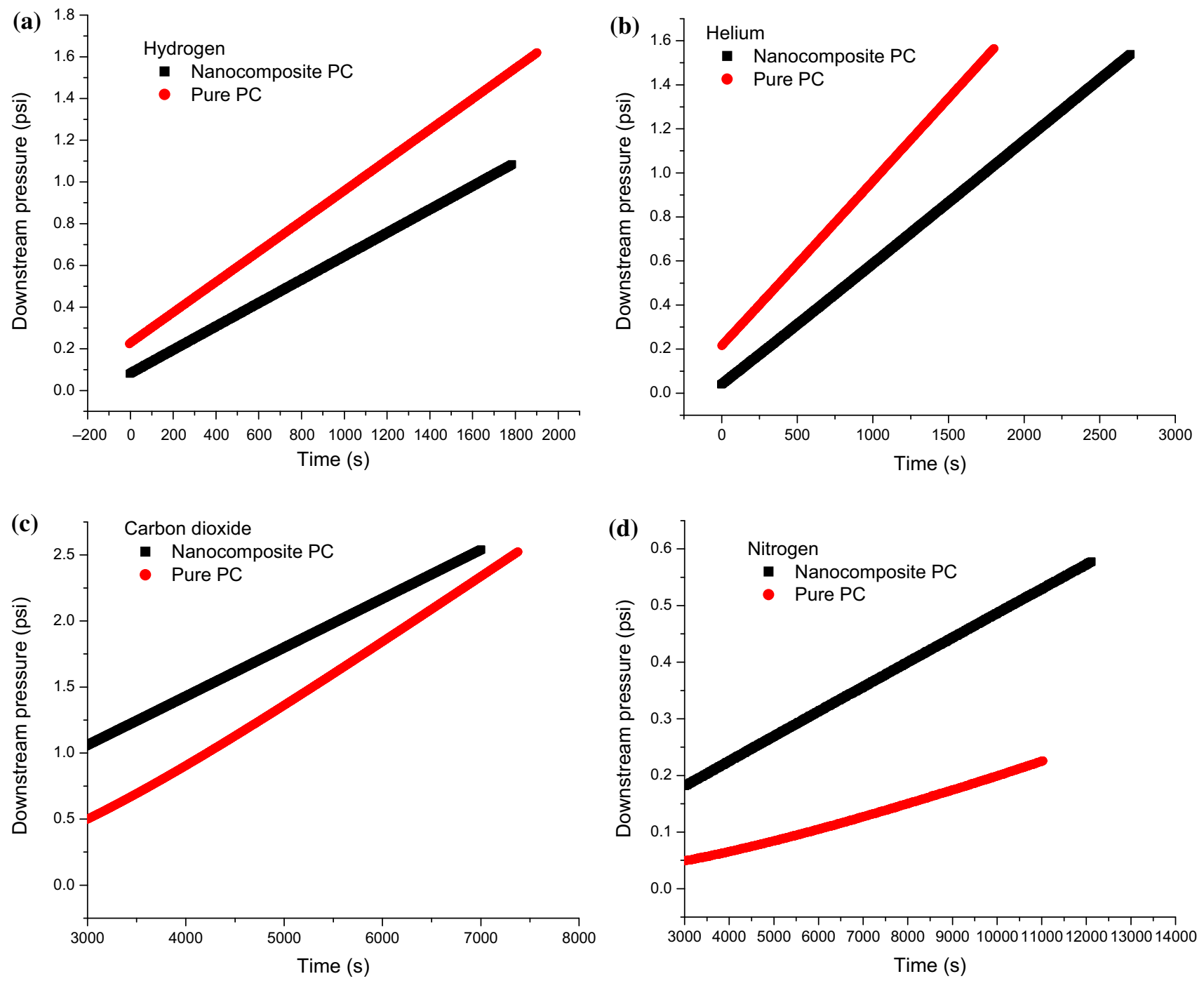

Figure 1. Graph of downstream pressure (psi) vs. time (s) after steady state for (a) hydrogen, (b) helium, (c) carbon dioxide and (d) nitrogen.

pure PC and PC-silica nanocomposite membrane, respectively. Figure 1 shows the downstream pressure $v s$. time curve of all experimental gases for pure PC and PC-silica nanocomposite membrane.

Interaction of penetrant gas molecules with the polymer matrix after steady state will aid in determining the diffusion coefficient. Another advantage of this is to optimize the diffusion coefficient of a given gas for a polymer, which can be used to estimate the solubility coefficient. Permeability coefficient is also given by the product of diffusivity coefficient and solubility coefficient as shown in equation (2). Initially, gases like $\mathrm{CO}_{2}$ and $\mathrm{N}_{2}$ show very low permeation rate for both the membranes. After steady state, the slopes of downstream pressure $v s$. time curve for carbon dioxide decreases from $4.58 \times 10^{-5} \mathrm{~cm}^{-\mathrm{Hg} \mathrm{s}^{-1}}$ in case of pure PC to $3.65 \times$ $10^{-5} \mathrm{~cm}-\mathrm{Hg} \mathrm{s}^{-1}$ for PC-silica nanocomposite membrane. In this work, the intercept value changes from -0.9028 to
-0.0265 for $\mathrm{CO}_{2}$; however thicknesses of both the membranes were different. Diffusion coefficient was calculated using the relation $D=l^{2} / 6 \theta$, where $l$ is the thickness of the membrane and $\theta$ is the time lag. It was found to be $16.4 \times 10^{-8}$ and $25.4 \times 10^{-8} \mathrm{~cm}^{2} \mathrm{~s}^{-1}$ for pure and nanocomposite membrane, respectively. Change in permeability by incorporation of silica nanoparticles alters the diffusion paths for carbon dioxide, which will modify the diffusion coefficient; however, solubility coefficient remains unaffected. Diffusion coefficient for $\mathrm{N}_{2}$ was found to be $5.37 \times 10^{-8}$ and $0.27 \times 10^{-8} \mathrm{~cm}^{2} \mathrm{~s}^{-1}$ for pure and nanocomposite membrane, respectively. It shows that both the diffusion and solubility coefficients for nitrogen alter and contribute to the overall permeability by incorporation of silica nanoparticles in polymer matrix.

Permeability of different gases with temperature is shown in figure 2. It shows an increase in permeability with increasing temperature for both the neat and composite membranes 


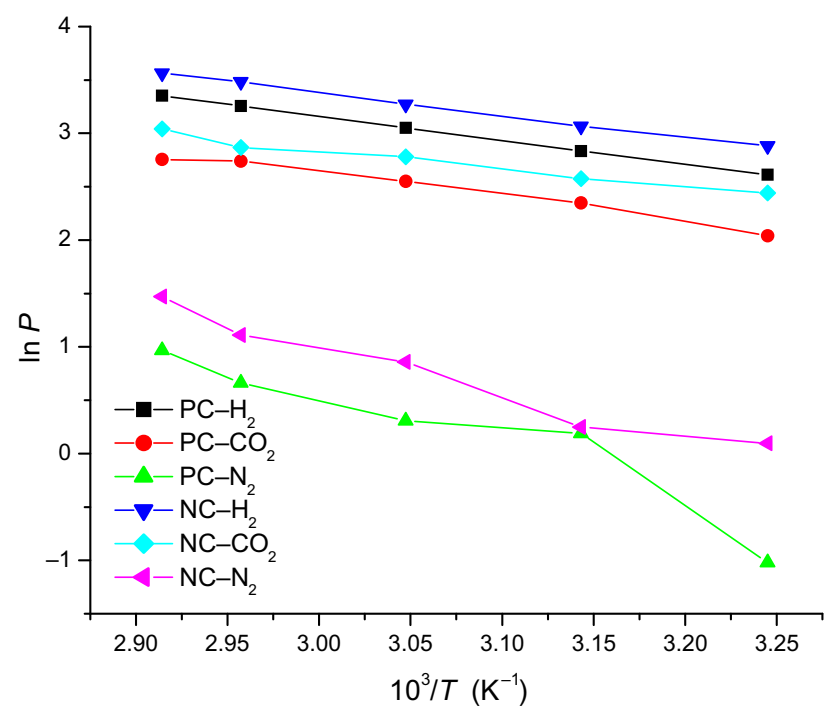

Figure 2. Graph of $\ln P$ vs. $103 / T$ for pure and nanocomposite polycarbonate.

as available in literature. Selectivity of different gas pairs with increasing temperature is shown in figure 3. It was found that the selectivity of $\mathrm{CO}_{2}-\mathrm{N}_{2}, \mathrm{H}_{2}-\mathrm{CO}_{2}$ and $\mathrm{H}_{2}-\mathrm{N}_{2}$ decreases for the nanocomposite membrane as compared with that of pure $\mathrm{PC}$ at $35^{\circ} \mathrm{C}$; however, permeability of all the measured gases increases for the nanocomposite membrane, which follows the trade-off relation of a glassy polymer. Selectivity for $\mathrm{CO}_{2}-$ $\mathrm{N}_{2}$ and for $\mathrm{H}_{2}-\mathrm{N}_{2}$ reduces by approximately the same factor, i.e., it reduces from 22 to 10 and 38 to 16 on adding nanoparticles. As temperature increases, selectivity reduces for both the membranes. Temperature provides additional energy by the increase of molecular vibrations of polymer chains; hence, it reduces selectivity. The amount of reduction in selectivity varies with the pair of gases chosen for the analysis. The selectivity for $\mathrm{H}_{2}-\mathrm{CO}_{2}$ was less affected due to nanoparticles as shown in figure $3 \mathrm{~b}$; silica nanoparticles play an important role in enhancing the permeability of hydrogen and carbon dioxide by maintaining their selectivity. On the other hand, temperature allows creation of additional open spaces for permeating gas molecules. The combined effect on gas permeability is discussed in the next section.

\subsection{Activation energy for permeation}

It is obvious from figure 2 that permeability increases with temperature according to the Van't Hoff relation [22]. Permeation also decreased in the following order: $\mathrm{H}_{2}>\mathrm{He}>\mathrm{CO}_{2}$ $>\mathrm{N}_{2}$ for both the pure and nanocomposite membrane in the operating range of temperature. In addition, the permeability for the nanocomposite membrane was found to be higher than that of unfilled PC for all gases in the experimental temperature range. The activation energies of permeation for all the four gases were found to decrease by different amounts for the nanocomposite membrane as compared
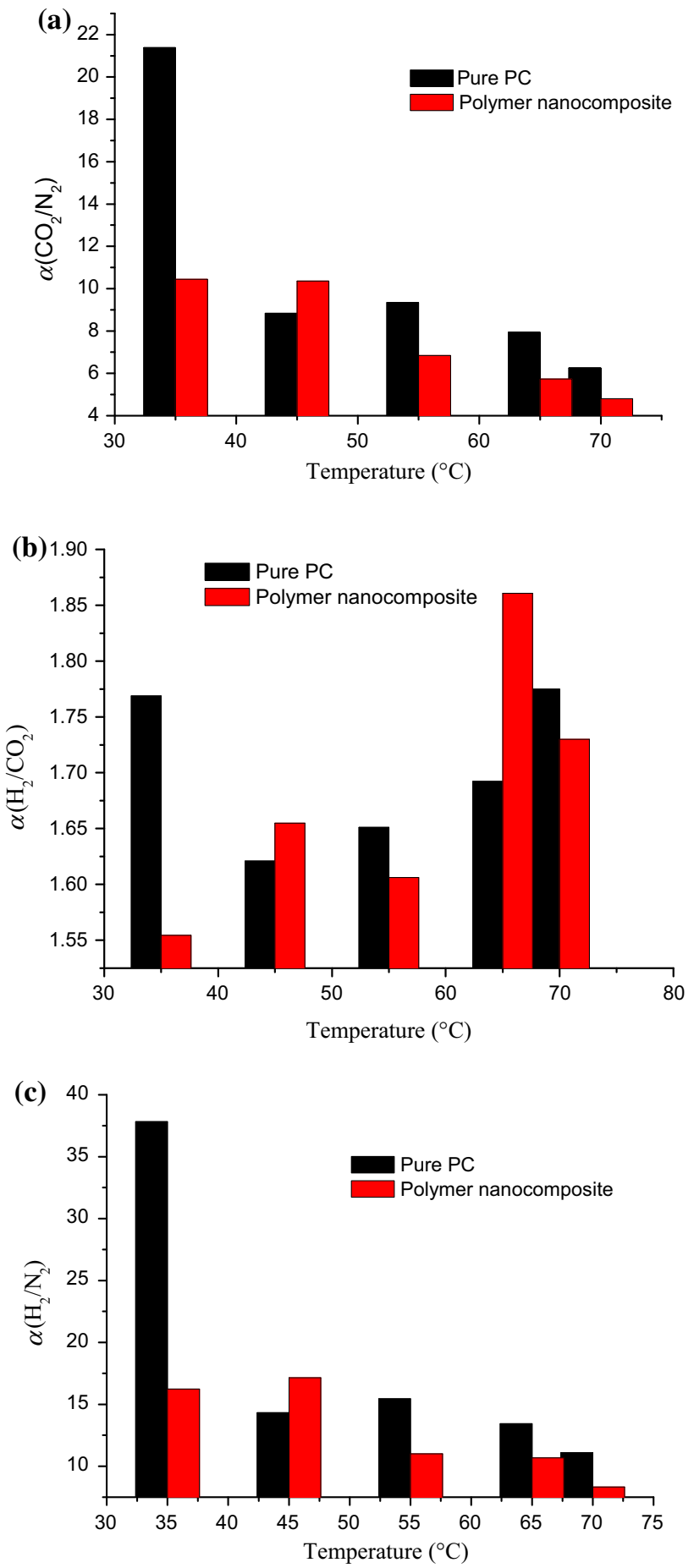

Figure 3. A graph of selectivity vs. temperature of (a) $\mathrm{CO}_{2} / \mathrm{N}_{2}$, (b) $\mathrm{H}_{2} / \mathrm{CO}_{2}$ and (c) $\mathrm{H}_{2} / \mathrm{N}_{2}$ for pure $\mathrm{PC}$ and polymer nanocomposite membrane.

with that of pure PC as shown in table 2. The error in activation energies was estimated using a linear regression method. It was found that temperature influences $\mathrm{N}_{2}$ permeability more than that of other gases. At higher temperatures, larger scale motion occurs, which produces larger penetratescale transient gaps to enable diffusion at relatively high 
Table 2. Activation energies of pure and polymer nanocomposite.

\begin{tabular}{|c|c|c|c|c|c|}
\hline \multirow[b]{2}{*}{ Sample } & \multirow[b]{2}{*}{$T_{\mathrm{g}}\left({ }^{\circ} \mathrm{C}\right)$} & \multicolumn{4}{|c|}{ Activation energy, $E_{\mathrm{p}}\left(\mathrm{kJ} \mathrm{mol}^{-1}\right)$} \\
\hline & & $\mathrm{H}_{2}$ & $\mathrm{He}$ & $\mathrm{CO}_{2}$ & $\mathrm{~N}_{2}$ \\
\hline Pure polycarbonate & 150 & $18.6 \pm 0.1$ & $16.8 \pm 0.5$ & $18.2 \pm 1.5$ & $44.0 \pm 8.7$ \\
\hline PC-silica nanocomposite & 148 & $17.4 \pm 0.4$ & $16.5 \pm 0.3$ & $14.4 \pm 1.4$ & $34.7 \pm 4.2$ \\
\hline Change in $E_{\mathrm{p}}(\%)$ & - & -6.45 & -1.78 & -20.87 & -21.13 \\
\hline
\end{tabular}

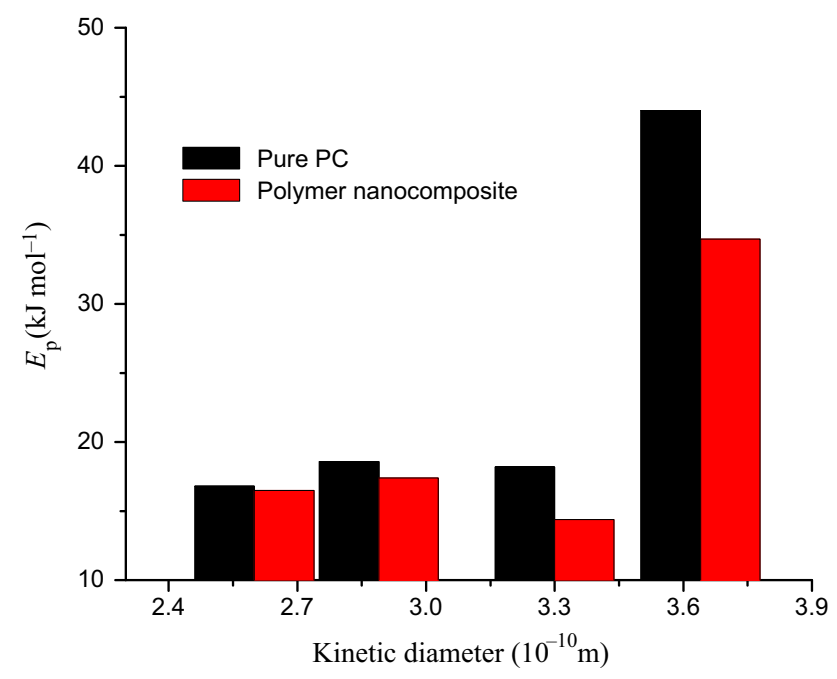

Figure 4. Graph of activation energy for permeation vs. kinetic diameter.

temperature [22]. Activation energy for permeation of $\mathrm{N}_{2}$ changes from 44 to $34.7 \mathrm{~kJ} \mathrm{~mol}^{-1}$. Existence of silica nanoparticles creates excess spaces in the interface of polymer and silica nanoparticles, which results in an increase in gas permeability. Figure 4 shows the change in activation energies with kinetic diameter of the gases. It is found that the polymer nanocomposite membrane shows lesser activation energies than those of pure polymer as shown in table 2. Also, activation energies increase with kinetic diameter and hence permeability reduces; this change is more prominent in larger gas molecules.

\subsection{DSC, SEM and DMA measurements}

The glass transition temperature $\left(T_{g}\right)$ of pure PC and PCsilica nanocomposite was estimated using TA universal analysis software. The measurements were repeated up to six cycles to avoid the effect of impurity on true value of glass transition temperature. $T_{\mathrm{g}}$ was determined as $150^{\circ} \mathrm{C}$ for pure $\mathrm{PC}$, which is in agreement with the literature value [27], whereas, $T_{\mathrm{g}}$ decreases slightly for PC-silica nanocomposite to $148^{\circ} \mathrm{C}$. This change in $T_{\mathrm{g}}$ may be due to the existence of silica nanoaprticles in the polymer matrix, which provides long-range segmental mobility of polymer chains [28];

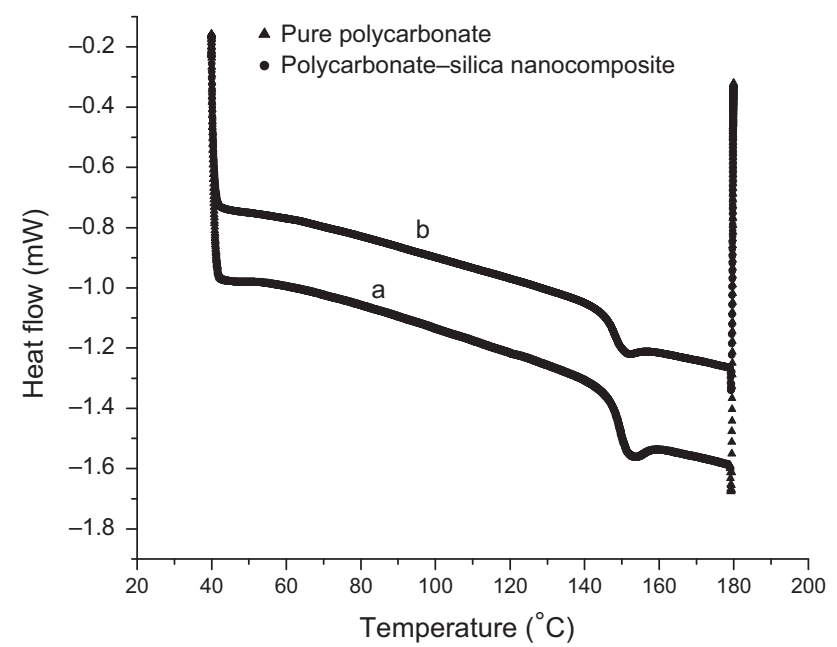

Figure 5. DSC thermogram of (a) pure polycarbonate and (b) PC-silica nanocomposite.

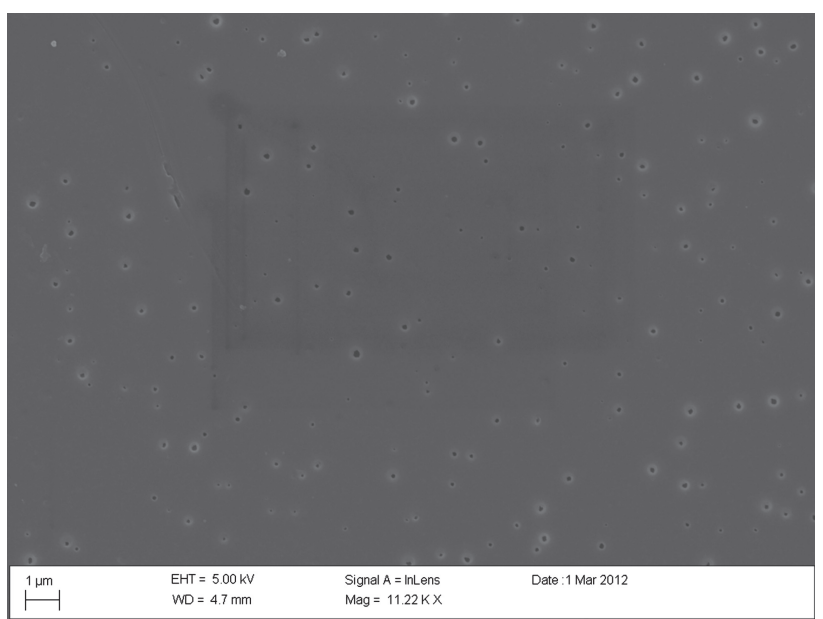

Figure 6. SEM image of PC-silica nanocomposite membrane.

however, concentration of nanoparticles may alter $T_{\mathrm{g}}$ to a certain extent. Comparative DSC thermograms of pure PC and PC-silica nanocomposite are shown in figure 5.

Silica nanoparticles play an important role in generating excessive space or free volume in polymer matrix. The surface morphology of polymer nanocomposite membrane as observed using the SEM is shown in figure 6; however, the 


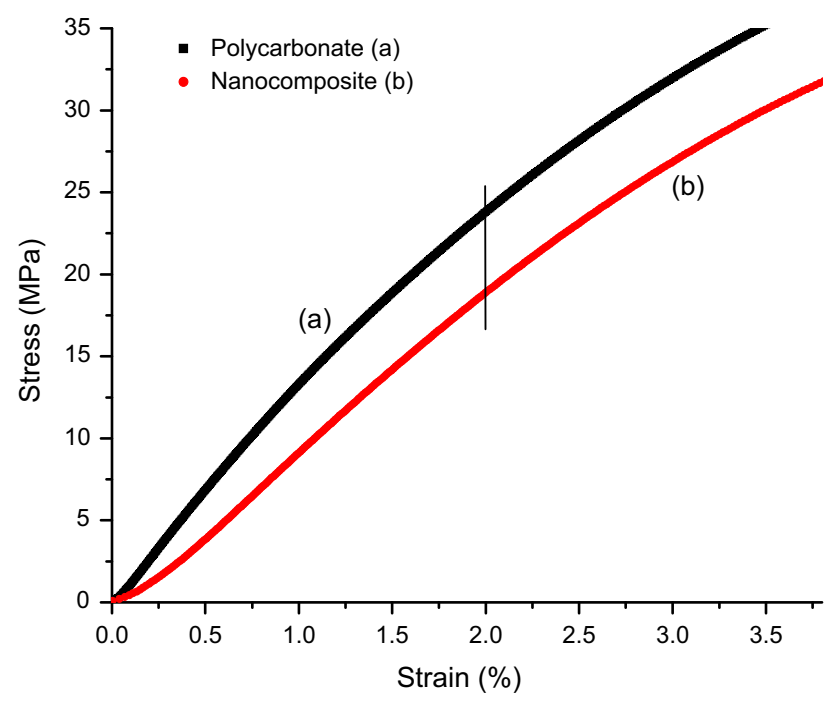

Figure 7. Stress vs. strain curve for pure $\mathrm{PC}$ and $\mathrm{PC}-$ silica nanocomposite.

size may depend on the quality of dispersion and degree of de-agglomeration. In the present case the average observed size of these spaces was 100-120 nm. These excessive spaces may lead to increase in gas permeability. Stress $v s$. strain curves for pure PC and PC-silica nanocomposite are shown in figure 7. A clear change has been observed for the composite; tangent modulus was found to be $12 \mathrm{MPa}$ for pure PC and 9.5 MPa for PC-silica nanocomposite. For 2\% strain, pure PC requires $24 \mathrm{MPa}$, while PC-silica nanocomposite for the same strain requires $19 \mathrm{MPa}$ of stress, which shows the evidence of modified structure due to composite formation [28].

\section{Conclusions}

Polymer-matrix composite membrane was prepared by incorporation of silica nanoparticles to investigate the effect of nanoparticles on transport properties and activation energy for permeation. Temperature provides additional energy by increase of the molecular vibrations of polymer chains; hence, it reduces selectivity for both the samples. Activation energy for permeation of all gases decreases by different factors. Glass transition temperature reduces slightly for the composite membrane. SEM reveals the confirmation of excessive spaces generated due to introduction of the inorganic silica nanoparticles at the surface of nanocomposite membrane. For the first time, the activation energy for permeation of polymer nanocomposite has been reported and found to decrease by different factors depending on the nature of gases, for all gases. These results can be explained on the basis of the excessive spaces generated due to incorporation of inorganic silica nanoparticles.

\section{Acknowledgements}

The author is thankful to the Department of Science and Technology, New Delhi, for supporting Fast Track young scientist and BOYSCAST scheme during the work (FTP/PS-32/2006 and BY/P-01/10-11). The author is also thankful to Dr Freeman's group, Chemical Engineering Department, University of Texas at Austin, TX, USA, for providing experimental facilities during the work.

\section{References}

[1] Balazs A C, Emrick T and Russell T P 2006 Science 3141107

[2] Zou H, Wu S and Shen J 2008 Chem. Rev 1083893

[3] Wei L, Hu N and Zhang Y 2010 Materials 34066

[4] Sharifzadeh E, Ghasemi I and Qarebagh A N 2015 Iran Polym. J. 241039

[5] Liu L, Li Y, Weng L, Cui W, Shi H and Wang C 2014 Iran Polym. J. 23987

[6] Merkel T C, Freeman B D, Spontak R J, He Z, Pinnau I, Meakin $\mathrm{P}$ et al 2002 Science 296519

[7] Vijay Y K, Acharya N K, Wate S and Avasthi D K 2004 Int. J. Hydrogen Energy 29515

[8] Pavlidou S and Papaspyrides C D 2008 Prog. Polym. Sci. 33 1119

[9] Ismail A F, Goh P S, Sanip S M and Aziz M 2009 Sep. Purif. Technol. 7012

[10] Robeson L M 1991 J. Membr. Sci. 62165

[11] Sanders D F, Smith Z P, Ribeiro Jr C P, Guo R, McGrath J E, Paul D R et al 2012 J. Membr. Sci. 409-410 232

[12] Bohning M, Hao N and Schonhals A 2013 J. Polym. Sci.: Polym. Phys. 511593

[13] Joly C, Samaihi M, Porcar L and Noble R D 1999 Chem. Mater. 112331

[14] Barrer R M, Barrie J A and Rogers M G 1963 J. Polym. Sci. A 12565

[15] Merkel T C, Freeman B D, Spontak R J, He Z, Pinnau I, Meakin $\mathrm{P}$ et al 2003 Chem. Mater. 15109

[16] Kim J H and Lee Y M 2001 J. Membr. Sci. 193209

[17] Moore T T and Koros W J 2005 J. Mol. Struct. 73987

[18] Acharya N K, Kulshrestha V, Awasthi K, Kumar R, Jain A K, Singh M et al 2006 Vacuum 81389

[19] Acharya N K, Kulshrestha V, Awasthi K, Jain A K, Singh M and Vijay Y K 2008 Int. J. Hydrogen Energy 33327

[20] Ghosal K and Freeman B D 1994 Polym. Adv. Technol. 5673

[21] Flaconnèche B, Martin J and Klopffer M H 2001 Oil Gas Sci. Technol. $\mathbf{5 6} 245$

[22] Costello L M and Koros W J 1992 Ind. Eng. Chem. Res. 31 2708

[23] Komatsuka T and Nagai K 2009 Polym. J. 41455

[24] Uddin M F and Sun C T 2010 Compos. Sci. Technol. 70223

[25] Bondar V I, Freeman B D and Pinnau I 2000 J. Polym. Sci. Part B: Polym. Phys. 382051

[26] Ahn J, Chung W J, Pinnau I and Guiver M D 2008 J. Membr. Sci. $\mathbf{3 1 4} 123$

[27] Moaddeb M and Koros W J 1997 J. Membr. Sci. 125143

[28] Morton W E and Hearle J W S 2008 Physical properties of textile fibres (Cambridge, England: Woodhead Publishing Ltd) 